Research Brief

\title{
Smart Snacks in School Legislation Does Not Change Self-Reported Snack Food and Beverage Intake of Middle School Students in Rural Appalachian Region
}

\author{
Georgianna Mann, PhD ${ }^{1,2, \dagger}$; Kathy Hosig, $\mathrm{PhD}^{3}$; Angang Zhang, $\mathrm{PhD}^{4, \dagger}$; Sumin Shen, $\mathrm{MS}^{3}$; \\ Elena Serrano, $\mathrm{PhD}^{3}$
}

\begin{abstract}
Objective: To assess the effects of the national Smart Snacks in School standards, which include nutrient and ingredient limitations for school competitive foods and beverages effective July, 2014, on student intake in low-income rural Appalachian middle schools.

Methods: Food-frequency questionnaires were administered to students before and after implementation. Multiple ordinal logistic regression models were conducted to examine effects from year of data collection, grade, and free or reduced price lunch participation rates.

Results: No significant changes were observed after implementation except a decrease in consumption of $1 \%$ or nonfat flavored milk at school.

Conclusions and Implications: Smart Snacks in School standards did not result in significant dietary changes in this study. Longitudinal studies could evaluate long-term impacts of nutrition standards.

Key Words: Smart Snacks, schools, competitive foods, à la carte, vending machines, adolescent (J Nutr Educ Behav. 2017;49:599-604.)
\end{abstract}

Accepted May 1, 2017.

\section{INTRODUCTION}

Children and adolescents aged 5-17 years spend the majority of their waking hours in school settings and consume $35 \%$ to $40 \%$ of their daily calories in schools. ${ }^{1}$ Schools are important avenues to promote healthy eating among transitioning adolescents to become independent purchasers, when long-term risk of obesity may persist. ${ }^{2}$

\footnotetext{
${ }^{1}$ Department of Nutrition and Hospitality Management, University of Mississippi, University, MS

${ }^{2}$ Department of Human Nutrition, Foods, and Exercise, Virginia Tech, Blacksburg, VA

${ }^{3}$ Virginia Polytechnic Institute and State University

${ }^{4}$ Department of Biostatistics, Merck \& Co, Inc

${ }^{\dagger}$ Drs Mann and Zhang were affiliated with the Virginia Polytechnic Institute and State University at the time this study was completed.

Conflict of Interest Disclosure: The authors' conflict of interest disclosures can be found online with this article on www.jneb.org.

Address for correspondence: Georgianna Mann, PhD, Department of Nutrition and Hospitality Management, 220 Lenoir Hall, PO Box 1848, University of Mississippi, University, MS 38655; Phone: (662) 915-2621; Fax: (662) 915-7039; E-mail: gmann89@vt.edu (C)2017 Society for Nutrition Education and Behavior. Published by Elsevier, Inc. All rights reserved.

http://dx.doi.org/10.1016/j.jneb.2017.05.338
}

foods and beverages sold in schools, based on the Institute of Medicine recommendations and Dietary Guidelines for Americans (Table).,

The Healthy, Hunger-Free Kids Act of $2010^{5}$ is based on the socioecological model. Smart Snacks specifically targets the school food environment of schools, which not only can influence availability and access to healthy foods but can alter social and cultural norms. $^{6}$

The goal of this study was to examine the effect of this policy on adolescents' snack food and beverage intake within rural Appalachia, especially considering that low socioeconomic status and rural lifestyle are tied to lower dietary quality and higher obesity rates. ${ }^{7,8}$ A secondary goal of the study was to examine the relationship between school poverty rates, determined by free or reduced price lunch rate $(\mathrm{F} / \mathrm{R})$ and intake of snack foods and beverages. Despite the multiple increased risk factors for obesity prevalent in this region, few studies focused specifically on this problem, likely because of the geographical barriers to accessing many 


\section{Foods}

General standard: foods must meet 1 general standard

- A grain product (>50\% whole grains by weight or whole grain as first ingredient ${ }^{2}$ )

- A fruit (can be dried), vegetable, dairy or protein (meat, bean, poultry, seafood, eggs, nuts, etc) or have these as first ingredient ${ }^{a}$

- A combination food with 0.25 cup fruit/vegetable

- Contain $10 \%$ of Daily Value of a nutrient of public health concern $(\mathrm{Ca}, \mathrm{K}$, vitamin $\mathrm{D}$, dietary fiber) until July 1, 2016 (after this it will not qualify)

- Fat exemptions: reduced-fat cheese, nuts and seeds, nut/seed butters, dried fruits with nuts/seeds and no added sweetener/fat, seafood with no added fat, part-skim mozzarella cheese

- Sugar exemptions: dried/dehydrated fruits or vegetables with no added nutritive sweeteners, dried fruits with nutritive sweeteners for processing/palatability, dried fruits with nuts/seeds and no added sweetener/fat

\section{Beverages}

$\leq 12$ oz as served

$\leq 12$ oz as served No limit
Nutrient standard: foods must meet all nutrient standards

- $\leq 200 \mathrm{cal} /$ portion as served

- $\leq 35 \%$ total calories from fat as served

- $<10 \%$ of total calories from saturated fat as served

- $0 \mathrm{~g}$ trans fat $(<0.5 \mathrm{~g}) /$ portion as served

- <230 mg sodium/portion as served (until July 1, 2016), <200 mg/portion as served (after July 1, 2016)

- $\leq 35 \%$ of weight from total sugars as served

- Overall exemptions: fruits (frozen/fresh/canned in juice/light syrup), vegetables (fresh/canned with minimal sugar)

- Entrée items as part of the National School Lunch Program/School Breakfast Program if it is sold as a competitive food on the day of service or the day after service in the National School Lunch Program/School Breakfast Program (must have $\leq 480 \mathrm{mg} /$ sodium and $\leq 350$ cal)

Unflavored low-fat, unflavored fat-free, or flavored fat-free milk; milk alternatives

$100 \%$ fruit or vegetable juice with or without carbonation Plain water, with or without carbonation

${ }^{\mathrm{a}} \mathrm{Can}$ be the second ingredient if the first is water.

Appalachian communities. ${ }^{9,10}$ It is possible that much of these children's diets consist of foods provided through the school system because of the high poverty rates. The hypothesis was that national implementation of Smart Snacks would improve snack food and beverage intake of middle school students in rural Appalachian middle schools.

\section{METHODS}

\section{Sample}

The researchers recruited only middle schools, defined as schools housing sixth- through eighth-grade students in southwest Appalachian Virginia with $\geq 50 \%$ of students eligible for $\mathrm{F} / \mathrm{R}$ National School Lunch Program (NSLP) meals, to participate in this study in spring, 2014 (before implementation) and spring, 2015 (after implementation). Schools were contacted using a randomized list of 23 qualifying middle schools in Appalachian Virginia. Of the 11 schools that were contacted, 3 declined to participate, which left a total sample of 8 schools (72.7\% response rate). ${ }^{11,12}$ Audits were also completed to assess compliance in the same 8 schools before and after implementation of standards in a parallel study. ${ }^{13}$

\section{Participants}

Trained graduate students guided participating middle school students through the questionnaire before allowing them to complete the remainder of the questionnaire on their own, assisting when necessary. Approximately 45 sixth-grade students completed questionnaires in each school before implementation. After implementation, questionnaires were administered to approximately 45 seventh-grade and 45 sixth-grade children per school. Principals in participating schools were instructed to identify classes from their respective schools to participate in the study and acquire consent from the respective teachers to minimize possible interference in the academic schedule. Often the required number of students was fulfilled by gym classes or individual classes of students. Sample size was determined based on a desired $80 \%$ probability that the study would successfully detect differences in student diets before and after implementation, determined by a minimal detectable difference of 0.22 times consumed per day (SD 1.50 times per day) of a food or beverage item on the survey instrument.

Only sixth-graders were selected before implementation because these students would be exposed first to more competitive foods compared with seventh-grade students. Sixthgraders were targeted because they are transitioning into more independent decision making regarding foods, because elementary schools tend to be more restrictive, offering few vending or á la carte items compared with middle schools. ${ }^{14}$ Both sixth- and seventh-graders were included in the after-implementation analysis to ensure there were no confounding effects by grade. It is possible that students surveyed before implementation also 
participated in the survey after implementation.

\section{Questionnaire}

The survey instrument consisted of sociodemographic questions including grade, gender, and frequency of lunch purchases; and the Beverage and Snack Questionnaire 2 (BSQ2). The BSQ2 was a modification of the BSQ, with the addition of flavored milk, water, and coffee or tea, designed for children aged 10-18 years. ${ }^{15,16}$ The 23-item questionnaire focused on the location (at school or away from school) and consumption of snack foods and beverages, particularly those high in solid fats and added sugars, and fruits and vegetables, which are often found in competitive and/or snack foods and beverages. ${ }^{15,17}$ The original BSQ was tested for validity; results ranged from 0.11 to 0.69 across food types (snacks, fruits and vegetables, etc) compared with a 4-day food record. ${ }^{15,18}$ Pearson correlation coefficients ranged from $r=.72$ to $r=.85$ per item.

Participation was voluntary and no personal information was obtained. Parental consent was not required for the anonymous survey. Study instruments and protocol were approved by the Virginia Polytechnic Institute and State University Institutional Review Board.

\section{Data Analysis}

The researchers used an ordinal logistic regression model to evaluate the effects of Smart Snacks implementation (year) on dietary intake. Within the ordinal logistic regression, the authors also tested for fixed effects: year, gender, and free/reduced lunch rates. Grade (6 and 7) and F/R rate were included as covariates. Frequency of consumption for all 23 food and beverage items were coded as never or less than once per week (0), 1 time/wk (1), 2-4 times/wk (2), 5-6 times/wk (3), 1 time/d (4), 2-3 times/ d (5), and $\geq 4$ times/d (6). Three separate analyses were conducted for frequency of consumption in school, because 1 school did not permit sociodemographic data to be collected owing to sensitivity issues. The 3 analyses allowed for testing of effects of different socioeconomic variables on dietary intake both in school and outside school: (1) a model including 7 schools with gender, grade, year and F/R rate as covariates; (2) a model including all 8 schools with year, grade, and $\mathrm{F} / \mathrm{R}$ rate as covariates; and (3) a model using 7 schools comparing diet and school lunch purchase frequency with school treated as a random effect (version 22.0.0, SPSS Statistics, IBM Corporation, Armonk, NY, 2013).

\section{RESULTS}

\section{Schools}

Based on a parallel study on the same 8 schools, $90 \%$ of á la carte foods were compliant with the standards after implementation, an increase from 36\% compliance before the standards. Further details describing audit data are provided elsewhere. $^{13}$

\section{Participants}

Average enrollment for the 8 participating schools was 104 sixth-grade students (range, 70-156 students) and 116 seventh-grade students (range, 60-160 students) in the 2013-2014 school year (before implementation) and 115 sixth-grade students (range, 59-149 students) and 103 seventhgrade students (range, 66-161 students) in the 2014-2015 school year (after implementation). ${ }^{19}$ Before implementation 416 sixth-grade students were surveyed; after implementation, 304 sixth-and 363 seventh-grade students were surveyed. Of the 7 schools with gender data, $54 \%$ of respondents identified as male. Overall $89.2 \%$ of the sample self-identified as white, $3.0 \%$ as African American, 1.1\% as Asian or Pacific Islander, $1.6 \%$ as Native American, and $3.2 \%$ as other; $1.9 \%$ preferred not to answer. Of this sample, 2.31\% identified as Hispanic or Latino.

\section{Self-Reported Snack Food Intake at School}

Foods with the highest consumption frequencies were fruit $(23.3 \%$ of students consumed it once or more per day), vegetables $(13.9 \%)$, chips $(10.1 \%)$, candy $(8.5 \%)$, and baked goods $(7.4 \%)$. Students who reported buying lunch were also more likely to report eating vegetables and consuming salty snacks.
Girls reported consuming fewer low or nonfat frozen desserts and less ice cream $(P<.05)$ and higher fruit consumption than did boys.

No significant differences in consumption of foods or beverages were found between sixth-grade before implementation and sixth-grade after implementation. Similarly, no significant differences were found between sixth-grade before implementation and seventh-grade after implementation for either foods or beverages, in or out of school.

The F/R eligibility rate by school was positively associated with both low or nonfat frozen desserts and ice cream consumption $(P<.05)$. It was also positively associated with increased vegetable consumption $(P<.01)$.

\section{Self-Reported Snack Beverage Intake at School}

The most frequently consumed beverages reported were water $(39.1 \%$ of students consumed it $\geq 1$ times/d), $1 \%$ or nonfat flavored milk (17.1\%), regular or $2 \%$ flavored milk (13.2\%), $100 \%$ juice $(13.4 \%)$, and regular or $2 \%$ unflavored milk (10.6\%). Few students reported consuming energy drinks, coffee, or tea. In contrast, fruit drinks, sports beverages, flavored water, and soda consumption was negatively associated with school lunch purchases. Significantly more girls reported more frequent consumption of plain water $(P<.01)$ whereas boys consumed more $100 \%$ juice $(P<.01)$, energy drinks, and $1 \%$ or nonfat flavored milk $(P<.001)$.

Before Smart Snacks implementation, a higher consumption of $1 \%$ or nonfat flavored milk occurred $(P<.05)$. More flavored water was consumed after implementation $(P<.05)$. No other changes by year were noted.

Again, differences existed between schools; school 8 consumed the most $100 \%$ juice and school 3 consumed the least $(P<.05)$. A higher $\mathrm{F} / \mathrm{R}$ rate was associated with increased 100\% juice consumption $(P<.05)$, $1 \%$ or nonfat flavored $(P<.01)$, regular or $2 \%$ flavored, $1 \%$ or nonfat unflavored, and regular or $2 \%$ unflavored milk $(P<.01)$. Frequency of consumption of all milk varieties except regular or 2\% unflavored milk was positively associated with buying lunches both before and after implementation. 


\section{Self-Reported Snack Food and} Beverage Intake Outside School

The snack foods with the highest consumption frequency were fruits $(37 \%$ of students consumed them once or more per day), vegetables (25.8\%), candy (20.8\%), and chips (20.5\%). The most commonly consumed beverages were water $(48.6 \%)$, soda $(29.3 \%)$, fruit drinks (22.7\%), and sports drinks (22.6\%). Similar gender differences were found for outside and in school. Girls reported a higher consumption frequency of vegetables $(P<.01)$ as well as higher consumption frequency of fruits $(P<.001)$ than did boys. Girls also reported higher water $(P<.001)$ and coffee $(P<.01)$ consumption than did boys. However, boys reported higher energy drink $(P<.001)$ and $1 \%$ or nonfat flavored milk consumption $(P<.01)$ than did girls.

No significant changes were noted in snack food and beverage intake outside school from before to after the implementation. The $\mathrm{F} / \mathrm{R}$ rate was negatively correlated with the consumption of soda $(P<.05)$ and positively correlated with regular or $2 \%$ flavored milk consumption outside school $(P<.001)$.

\section{DISCUSSION}

The current study found that the Smart Snacks standards did not result in significant shifts in dietary components of middle school students in this sample of rural Appalachian middle schools, both in and out of school. The only significant change was that consumption of $1 \%$ or nonfat flavored milk decreased after the legislation, which was possibly a negative consequence, considering that only $22 \%$ of boys and $15 \%$ of girls aged 9-13 years were meeting the adequate intake for dietary calcium. ${ }^{20}$

It is possible that although the school snack food environment changed positively, children may have brought foods from home. In addition, not all school foods were compliant with the standards, which still offered an opportunity for students to access unhealthy foods. ${ }^{13}$ In another study, compliance of á la carte foods to new snack legislation in this sample of schools rose from $36.0 \%$ to $90.0 \%$. However, many schools in that study had fundraisers and snack stores open to students. ${ }^{12,13}$

There were few changes to dietary patterns as a result of the standards; this could be explained by the introduction of copycat snacks. Food companies were quick to respond to the Smart Snacks standards and reformulated popular snack items to maintain school customers. Copycat snacks appeared similar to regular products found on the market but were reformulated versions that often had smaller portion sizes and were lower in fat, sodium, or sugar and were available only at school, with the intent purpose of meeting Smart Snacks legislation. $^{21}$ Copycat snacks generally included chips, fruit snacks, baked goods, and salty snacks. These copycat snacks were common in the audits of schools after implementation of the standards. ${ }^{13}$ Without knowing there were copycat snacks and about the possible nutrient differences, students would not be able to discriminate between reformulated and original products in the BSQ2. The survey included low-fat and fullfat options, but it is unlikely students could discern the difference between reformulated and original products owing to similarities in packaging. Along these lines, students may have consumed fruits and vegetables in less healthy forms such as fried, packed in syrup, or included in combination dishes such as casseroles. The BSQ2 instrument has examples of vegetables (salad, peas, green beans, or corn) and fruits (bananas, apples, or grapes) but excluded only fried potatoes and fruit juices. This BSQ2 provided some common competitive food and beverage items but was not comprehensive and was based on self-reported data. It is possible that the instrument was not sensitive enough to detect changes in solid fats and added sugars sold in schools. Many of the foods were not substituted with different food types but instead with the copycat snacks. Despite these limitations, the BSQ2 was an appropriate tool for the age group and the only known questionnaire verified for this age group that included items often sold in schools. ${ }^{18}$

Owing to concerns of privacy, 1 school did not permit the inclusion of sociodemographic information within the study. The school sample size was relatively small, and schools var- ied even within the same district. The observational period was also short, and a longer data collection period may have yielded stronger results. Schools also faced turnover of cafeteria and office staff, which could have affected results presented here. For example, 1 school added noncompliant flavored water vending machines when a new principal was hired. Although this report fills an important research gap by studying rural, high-poverty middle schools in this unique highly disparate area, it is not widely generalizable. ${ }^{9}$

\section{Snack Foods}

Chips were 1 of the more popular snacks among children participating in the study. Chips, as well as baked goods such as cookies, were frequently offered in cafeterias as á la carte options. $^{12}$ Although vegetable and fruit consumption was often reported, children were not meeting their recommended intake of fruits and vegetables. ${ }^{22}$

Consumption patterns of students reflected their school food environment, with highly variable food options even within school districts. ${ }^{23}$ Association of $\mathrm{F} / \mathrm{R}$ rate and foods served with NSLP meals was likely attributed to participation in NSLP, which had strict standards. A higher $\mathrm{F} / \mathrm{R}$ rate was associated with increased consumption of fruits and vegetables, which could be the result of higher NSLP participation, a trend noted by other research. ${ }^{24}$ Both vegetable consumption and salty snack consumption was positively associated with a higher rate of self-reported lunch purchases, which emphasized the vegetable component of the school meal and the availability of salty snack foods sold alongside the school meals á la carte. Students may have been purchasing these items to supplement their school lunches. ${ }^{25}$ Another interesting finding was that $\mathrm{F} / \mathrm{R}$ rate was positively correlated with the consumption of fruit, ice cream, and low-fat or nonfat frozen desserts. Dessert items often were offered alongside the school meal.

Gender differences in consumption frequency included higher fruit consumption by girls and higher ice cream consumption by boys. High fruit consumption by girls and higher 
ice cream consumption by boys was found in other studies and was consistent with these data. ${ }^{26,27}$

\section{Snack Beverages}

Whereas $1 \%$ or nonfat flavored milk declined between baseline and after implementation, students also reported more frequent consumption of flavored water. Decreases in $1 \%$ or nonfat flavored milk consumption frequency from before to after implementation could be attributed to decreased NSLP program participation over time. ${ }^{28}$ Milk consumption could have declined as a result of increased flavored water consumption, displacing typical milk consumption.

Water, flavored milk, regular or $2 \%$ unflavored milk, and 100\% juice were the most frequently consumed beverages at school. Similar to snack foods, a higher $\mathrm{F} / \mathrm{R}$ rate was associated with higher consumption of 100\% juice and milk, beverages that are included in an NSLP meal.

All milk varieties were positively associated with the $\mathrm{F} / \mathrm{R}$ rate. All milk varieties except regular or $2 \%$ unflavored milk were positively associated with the frequency of school meals purchased during the week. It is likely that most of the milk consumed by students was included in their NSLP meal, but some students may have confused the many milk options on the BSQ2.

A common beverage offered á $l a$ carte by all schools participating in this study was $100 \%$ juice. ${ }^{12}$ Some schools offered more brands and varieties of juice and had higher consumption rates compared with other schools that offered as few as 1 brand of juice á la carte with no juice in vending machines or school stores.

Fruit drinks, sports beverages, flavored water, and soda were negatively associated with school meal purchases. None of these items were offered á la carte but sports beverages and flavored water were offered in vending machines outside the school cafeterias in select schools. A high report of sports beverage consumption was noted in school 6 , where 4 nondiet sports beverage vending machines were available to students as well as a school store with these items available for purchase. Access to such school stores were associated with increased sugar-sweetened beverage consumption. ${ }^{29}$ Lower sports beverage and soda consumption was reported in schools without sales outside á la carte.

Higher water consumption by girls and higher milk consumption by boys was consistent with national study findings. ${ }^{30}$ Higher frequency of juice consumption in boys could be explained by the high frequency of water consumption in girls, which suggested that water displaced 100\% juice and milk consumption in their diets. Furthermore, lower energy drink consumption in girls was found elsewhere. ${ }^{31}$

\section{Outside School}

An interesting finding in the current study was that a higher $\mathrm{F} / \mathrm{R}$ rate was negatively correlated with the consumption of regular soda outside school. There are several possible reasons for this. Although low-income families tend to consume more sugar-sweetened beverages, high NSLP participation may have a spillover effect on healthy eating outside the lunchroom. ${ }^{32}$ Another possible explanation is that parents who elect to have their children enrolled in the NSLP may be more inclined to have a healthier eating environment at home. It is likely that the $F / R$ rate and milk consumption correlation were positive because students became accustomed to drinking flavored milk. Gender consumption patterns were similar to inschool consumption patterns.

The primary limitations of this study were the small school sample size and limited generalizability of the sample. Further limitations included a lack of repeated-measures design and a short time period of evaluation. Although the BSQ2 was designed to measure common foods in schools, it did not assess consumption of nuts, cereals, meat jerky, yogurts, cheese, or sweet snack mixes, which were some items offered in the current sample of schools.

\section{IMPLICATIONS FOR RESEARCH AND PRACTICE}

Consumption frequency of foods and beverages often sold as competitive foods did not change significantly with the implementation of the new Smart Snacks standards. However, sig- nificant differences in consumption frequency of foods sold as part of the NSLP meals varied by the F/R rate of schools. Future research could compare school compliance levels with NSLP standards and competitive foods standards on student dietary intake. It may also be prudent to study student dietary intake over a longer time and examine effects of school competitive food policy on weight status.

\section{ACKNOWLEDGMENTS}

The authors would like to thank the school principals, cafeteria managers, staff, and students in southwest Appalachian Virginia for their participation in the study. They also thank Yara El Haddad, Kimberly Birkett, and Kirsten Smith, who provided support for data collection. Internal funding for this project was provided by Virginia Tech's College of Agriculture and Life Sciences, Blacksburg, VA.

\section{REFERENCES}

1. Glickman D, Parker L, Sim LJ, Cook H, Miller EA, eds. Accelerating Progress in Obesity Prevention: Solving the Weight of the Nation. Washington, DC: National Academies Press; 2012.

2. Freedman DS, Mei Z, Srinivasan SR, Berenson GS, Dietz WH. Cardiovascular risk factors and excess adiposity among overweight children and adolescents: the Bogalusa Heart Study. J Pediatr. 2007;150:12-17.e12.

3. Schneider LM, Schermbeck RM, Chriqui JF, Chaloupka FJ. The extent to which school district competitive food and beverage policies align with the 2010 Dietary Guidelines for Americans: Implications for federal regulations. J Acad Nutr Diet. 2012;112: 892-896.

4. Kramer-Atwood JL, Dwyer J, Hoelscher DM, Nicklas TA, Johnson RK, Schulz G. Fostering healthy food consumption in schools: focusing on the challenges of competitive foods. J Am Diet Assoc. 2002;102: 1228-1233.

5. US Department of Agriculture. The Healthy, Hunger-Free Kids Act of 2010. http://www.fns.usda.gov/sites/ default/files/HealthyHungerFreeKidsAc tof2010.pdf. Accessed November 10, 2015. 
6. Boyle MA. Understanding and achieving behavior change. In: Boyle MA, ed. Community Nutrition in Action: An Entrepreneurial Approach. 7th ed. Boston, MA: Cengage Learning; 2017:73-98.

7. Johnson JA III, Johnson AM. Urbanrural differences in childhood and adolescent obesity in the United States: a systematic review and meta-analysis. Childhood Obes. 2015;11:233-241.

8. Datar A, Chung PJ. Changes in socioeconomic, racial/ethnic, and sex disparities in childhood obesity at school entry in the United States. JAMA Pediatrics. 2015;169:696-697.

9. GeoHealth Innovations, Community Health Solutions. The 2013 Virginia Atlas of Community Health. http:// atlasva.org. Accessed January 15, 2015.

10. Economic Development Research Group, Inc. Appalachian Development Highway System Economic Analysis Study: synthesis of findings to date. https://www.arc.gov/assets/research_re ports/ADHSEconomicAnalysisStudy SynthesisofFindingstoDate.pdf. Accessed December 7, 2016.

11. Virginia Department of Education, School Nutrition Program School Year 2012-2013 National School Lunch Program (NSLP) Free and Reduced Price Eligibility Report. http://www. doe.virginia.gov/support/nutrition/stat istics/. Accessed December 7, 2016.

12. Mann G, Kraak V, Serrano E. The availability of competitive foods and beverages to middle school students in Appalachian Virginia before implementation of the 2014 Smart Snacks in School standards. Prev Chron Dis. 2015;12:1-5.

13. Mann G, Kraak V, Serrano E. Smart Snacks in School standards in Appalachian Virginia middle schools. Health Behav Policy Rev. 2017;4:245-255.

14. Kubik MY, Wall M, Shen L, et al. State but not district nutrition policies are associated with less junk food in vending machines and school stores in US public schools. J Am Diet Assoc. 2010; 110:1043-1048.

15. Neuhouser ML, Lilley S, Lund A, Johnson DB. Development and validation of a beverage and snack questionnaire for use in evaluation of school nutrition policies. I Am Diet Assoc. 2009;109:1587-1592.

16. The Network for a Healthy California, California Department of Public Health. Beverage and Snack Questionnaire. https://food-hub.org/files/resources/Net work-Compendium.pdf. Accessed May 22, 2017.

17. Johnson DB, Bruemmer B, Lund AE, Evens CC, Mar CM. Impact of school district sugar-sweetened beverage policies on student beverage exposure and consumption in middle schools. $J$ Adolesc Health. 2009;45(3 suppl):S30-S37.

18. Kolodziejczyk JK, Merchant G, Norman GJ. Reliability and validity of child/adolescent food frequency questionnaires that assess foods and/or food groups. J Pediatr Gastr Nutr. 2012;55:4-13.

19. Virginia Department of Education, School Nutrition Program. School summaries by ethnicity, grade, and gender. http://www.doe.virginia.gov/ statistics_reports/enrollment/fall_member ship/report_data.shtml. Accessed May 22, 2017.

20. Bailey RL, Dodd KW, Goldman JA, et al. Estimation of total usual calcium and vitamin D intakes in the United States. J Nutr. 2010;140:817-822.

21. Wilking C. Copycat snacks in schools. http://www.phaionline.org/wp-content/ uploads/2014/05/PHAI-Copy-Cat-SnacksIssue-Brief-FINAL.pdf. Accessed September 14, 2014.

22. Arbury S, Jacklitsch B, Farquah O, et al. Vital signs: fruit and vegetable intake among children-United States, 2003-2010. MMWR. 2014;63:671-676.

23. Demissie Z, Brener N, McManus T, Shanklin S, Hawkins J, Kann L. School health profiles 2014. http://www.cdc. gov/healthyyouth/data/profiles/pdf/2014/ 2014_profiles_report.pdf Accessed December 16, 2015.

24. Longacre MR, Drake KM, Titus LJ, et al. School food reduces household income disparities in adolescents' frequency of fruit and vegetable intake. Prev Med. 2014;69:202-207.

25. Farris AR, Misyak S, Duffey KJ, Mann GR. A comparison of fruits, vegetables, sugar-sweetened beverages, and desserts in the packed lunches of elementary school children. Childhood Obes. 2015;11:275-280.

26. Caine-Bish NL, Scheule B. Gender differences in food preferences of schoolaged children and adolescents. J Sch Health. 2009;79:532-540.

27. Munoz KA, Krebs-Smith SM, BallardBarbash R, Cleveland LE. Food intakes of US children and adolescents compared with recommendations. Pediatrics. 1997;100:323-329.

28. Food and Nutrition Service, US Department of Agriculture. National School Lunch Program: participation and lunches served. http://www.fns. usda.gov/sites/default/files/pd/slsummar. pdf. Accessed November 17, 2014.

29. Cullen KW, Zakeri I. Fruits, vegetables, milk, and sweetened beverages consumption and access to à la carte/ snack bar meals at school. Am J Public Health. 2004;94:463-467.

30. Drewnowski A, Rehm CD, Constant F. Water and beverage consumption among children age 4-13y in the United States: analyses of 20052010 NHANES data. Nutr J. 2013;12: 85.

31. Larson N, DeWolfe J, Story M, Neumark-Sztainer D. Adolescent consumption of sports and energy drinks: linkages to higher physical activity, unhealthy beverage patterns, cigarette smoking, and screen media use. J Nutr Educ Behav. 2014;46:181-187.

32. Ogden CL, Kit BK, Carroll MD, Sohyun P. Consumption of sugar drinks in the United States, 20052008. NCHS Data Brief. 2011;71:1-8. 


\section{CONFLICT OF INTEREST}

The authors have not stated any conflict of interest. 